\title{
Open Access and Scopus: A New Approach to Scientific Visibility From the Standpoint of Access
}

\author{
Sandra Miguel \\ Universidad Nacional de La Plata, Facultad de Humanidades y Ciencias de la Educación, \\ Departamento de Bibliotecología, C/ 48 e/ 7 y 8 La Plata, 1900, Buenos Aires, Argentina, and \\ Grupo de Investigación SCImago, C/ Albasanz, 26-28. Madrid, Spain. E-mail: sandra@fcnym.unlp.edu.ar \\ Zaida Chinchilla-Rodríguez and Félix de Moya-Anegón \\ Consejo Superior de Investigaciones Científicas, Centro de Ciencias Humanas y Sociales, \\ Instituto de Políticas y Bienes Públicos, Grupo de investigación SCImago, C/Albasanz, 26-28, Madrid, Spain. \\ E-mail: \{zaida.chinchilla, felix.demoya\}@cchs.csic.es
}

\begin{abstract}
The last few years have seen the emergence of several open access (OA) options in scholarly communication, which can be grouped broadly into two areas referred to as gold and green roads. Several recent studies have shown how large the extent of OA is, but there have been few studies showing the impact of $O A$ in the visibility of journals covering all scientific fields and geographical regions. This research presents a series of informative analyses providing a broad overview of the degree of proliferation of OA journals in a data sample of about 17,000 active journals indexed in Scopus. This study shows a new approach to scientific visibility from a systematic combination of four databases: Scopus, the Directory of Open Access Journals, Rights Metadata for Open Archiving (RoMEO)/Securing a Hybrid Environment for Research Preservation and Access (SHERPA), and SciMago Journal Rank] and provides an overall, global view of journals according to their formal OA status. The results primarily relate to the number of journals, not to the number of documents published in these journals, and show that in all the disciplinary groups, the presence of green road journals widely surpasses the percentage of gold road publications. The peripheral and emerging regions have greater proportions of gold road journals. These journals belong for the most part to the last quartile. The benefits of OA on visibility of the journals are to be found on the green route, but paradoxically, this advantage is not lent by the $O A$, per se, but rather by the quality of the articles/journals themselves regardless of their mode of access.
\end{abstract}

Received August 3, 2010; revised February 18, 2011; accepted February 28, 2011

C 2011 ASIS\&T • Published online 11 April 2011 in Wiley Online Library (wileyonlinelibrary.com). DOI: 10.1002/asi.21532

\section{Introduction}

The scientific community is a key platform for research activity, and publishing is the formal mechanism through which researchers make contributions to the body of scientific knowledge. Thus, the documents configuring the bibliographic dimension of a discipline also can be seen as systems of production and dissemination of knowledge (Keresztesi, 1982). Journals and databases are the protagonists in scientific communication. Their value and implications for science go beyond purely bibliographic relevance, as they become the main focus of bibliometric studies, and enable researchers and policy makers to assess developments and trends within the realms of science (Borgman \& Furner, 2002).

In view of the tremendous volume of articles currently published worldwide, journal quality is a main criterion for researchers aiming to report their research findings. Indeed, journal quality may be even more important than is free access or visibility (Warlick \& Vaughan, 2007). Journal quality depends largely upon compliance with editorial standards for the presentation and organization of contents to ensure the scientific rigor of all articles published and thereby fortify the journal's standing. Yet, quality cannot be expressed by one simple number; there are aspects impossible to quantify, which are linked to the peer-review process. The specialists in a field, or peers, establish thresholds for the reliability of reported results, and by filtering out sound research articles amid the vast number of journals in the information market, they determine the inherent quality of publications.

Visibility, or "impact," is in turn determined by how avidly published work is received by the academic or scientific community. Here is where bibliometrics comes in as a useful extrinsic tool, complementing peer review or recounting 
what peers have validated. Visibility is therefore an indirect means of appraising the quality of publications, which leads to the question of how to best measure it. Traditionally, the impact of publications was measured literally, through citations received considered as the observed impact, or in terms of anticipated impact or the journal impact factor (IF). According to Harnad et al. (2004), impact measures the extent to which the results of research findings are read, used, cited, and applied in future research efforts. It is a gauge of progress and productivity that has implications for the career of the researchers in question (e.g., salary, project financing, recognition, awards, etc.) and for the institutions they belong to, which will likewise benefit from financing or prestige. The funding agencies also obtain returns from such an investment.

For decades, experts have been calling for the combined use of indicators to shed light on scientific productivity and its impact (Martin, 1996; Moed, Van Leeuwen, \& Reedijk, 1999; Rousseau and the STIMULATE 8 Group, 2009). Current initiatives may entail recounts of downloaded documents or social network analysis. Some of them, such as the projects Counting Online Usage of Networked Electronic Resources (COUNTER; http://www.projectcounter.org/) or Metrics from Scholarly Usage of Resources (MESUR; http://www.mesur.org/MESUR.html), try to weigh aspects of use that will complement already-defined factors of publication quality. MESUR analyzed 39 aspects of impact or visibility to see how they are interrelated and how precise and comprehensive they are in representing scientific impact. The results reconfirmed that the concept of quality/visibility is multidimensional and cannot be gauged by any single indicator or initiative. Complementary elements are needed to provide relatively objective and reliable information (Bollen, Van de Sompel, Hagberg, \& Chute, 2009).

Along these lines, full-text access of articles is considered to be one factor influencing the odds of consultation, retrieval, and citation of a document (Davis, et al., 2008; Hajjem, Harnad, \& Gingras, 2005; Moed, 2007; Norris, Oppenheim, \& Rowland, 2008).

The open access (OA) initiative regarding scientific literature proposes free access to publications as an alternative to the traditional model of distribution and access by subscriptions, which was the mainstay of journals for some 300 years. OA allows users to read, download, copy, distribute, print out, search, or link to the complete texts of the articles without any economic, legal, or technical barriers other than those intrinsic to the Internet (Budapest Open Access Initiative, 2001). The sole restriction for reproduction and distribution in the realms of OA is that authors hold control of the integrity of their work and the right to be properly acknowledged and cited.

In the Budapest Open Access Initiative Declaration (2001), two routes were established for achieving OA: the gold road, or publication of articles in OA journals, and the green road, which consists of the self-archive or deposit of all articles published in traditional journals, on authors' web pages, or in institutional/thematic repositories that are OA either before (preprint) or after (postprint) their publication.
These repositories, then, are archives of academic-scientific material available on the web containing articles published by researchers of a given institution or from a given field of knowledge (Chan, 2004). A variant of these models is the hybrid journal. This type of journal may require subscription, but the author is given the possibility of paying an established tariff so that the article will be freely available to readers without cost. One such example is the journal Proceedings of the National Academy of Sciences, USA. Others allow free access to articles only after a period of embargo (Abad, González, \& Martínez, 2006).

To increase visibility and promote the use of gold road journals, the Directory of Open Access Journals (DOAJ) was created (http://www.doaj.org/).This directory takes in all the international journals that ascribe to the OA movement, a number that is growing by leaps and bounds-from 1,400 titles in early 2005 to 5,138 as of June 2010 . Yet, this figure represents just $20 \%$ of the total number of academicscientific peer-viewed journals currently put out worldwide (Ulrich's International Periodicals Directory, 2010).

Harnad (2004) argued that the green road is the only option that would lead to $100 \%$ OA in the near future because it does not require complete restructuring of the system of scientific publication. He also urged institutions to create repositories according to the OAI protocol. The green road also offers incentives - promotions or funding-for authors who deposit their research results and harvest positive impact. Thus, authors can continue to publish their articles in the journals they choose (even if payment is involved) while also providing free access to their work through the version in the repository. The permission for self-archiving should be granted by journal publishers. Information about journal editorial policy and copyright with respect to the self-archive of some 700 publishing companies can be obtained through Securing a Hybrid Environment for Research Preservation and Access (SHERPA)/Rights Metadata for Open Archiving (RoMEO) (www.sherpa.ac.uk/romeo.php).

Meanwhile, the choice of data sources for carrying out macro-level studies of the situation and impact of OA on the publishing industry and on the scientific community is still an area of controversy. Jacsó (2006) insisted that OA sources do not replace the traditional bibliographic databases but complement them. Traditionally, the source of information used for bibliometric studies was the joint set of databases belonging to the Web of Science (WoS) of Thomson Reuters: the Science Citation Index, the Social Science Citation Index, and the Arts and Humanities Citation Index. One of their strong points is their multidisciplinary and international nature. These databases contain information from some 10,000 scientific journals and have become tools of world reference for information retrieval and for studies evaluating science. However, the appearance on the market of the SCOPUS database, by Elsevier, with a coverage of over 17,000 journals, together with the development of new tools for bibliometric analysis based on this source, such as the SCImago Country \& Journal Rank (SJR; SCImago, 2007) has helped complement and broaden analyses drawn from other sources. 
Ever since its early days, the SCOPUS database has been a subject of analysis (Codina, 2005; Fingerman, 2005; Jacsó, 2005, 2010; La Guardia, 2005), with comparisons of coverage, accessibility, usability, and price between this tool and the WoS. (Deis \& Goodman, 2006; Fingerman, 2006) or comparing these two products with Google Scholar (Bakkalbasi, Bauer, Glover, \& Wang, 2006). We shall avoid exhaustive mention of the profuse literature surrounding SCOPUS and simply note that certain limitations (Jacsó, 2008a,b,c, 2010) accompany the tremendous endeavor undertaken by Elsevier.There are still journals with important gaps regarding coverage and the country of affiliation. Such weaknesses must be remedied since they may have broad repercussions. For instance, the Organisation for Economic Co-Operation and Development has used SCOPUS as its main source of data for research into research, to foment a Strategy of Innovation to help governments raise their level of innovative production (Tomizawa, 2008). Similarly, since February 2009, the Australian Research Council has used this database for citation studies at its universities in the framework of the Excellence in Research for Australia program (Australian Research Council, 2009).

Notwithstanding, the levels of chronological, geographic, and thematic coverage attained by the WoS and SCOPUS are indeed sufficient for guaranteeing relevant and reliable findings (Braun, Glänzel, \& Schubert, 2000; Moya-Anegón et al., 2007). Both Thomson Reuters (http://thomsonreuters.com/) and Elsevier (http://elsevier.com) have stated that they have no restrictions in their selection policies with respect to electronic journals, and apply the same quality criteria as for the traditional journal. Moreover, their use of these sources - which feature inclusion of bibliographic references and institutional affiliations of all the authors-facilitates extensive posterior bibliometric analyses.

However, some studies have looked at the coverage of these sources in terms of the economic model of the journals, and of their value and implications for detecting research trends in different fields of knowledge. Harnad et al. (2004) found that $10 \%$ of the OA journals were gold road ones, and $90 \%$ were green road. However, if a journal adopts the green road to OA, allowing some form of self-archiving by the authors, this does not mean that articles published in it are actually deposited or self-archived. In fact, just 10 to $20 \%$ of the articles in green journals were self-archived. This suggests a lack of balance in the influence of OA on the publishing industry and on the scientific community.

A study by the Pontificia Universidad Católica de Valparaíso de Chile (2009) found that of the total journals registered under the Journal Citation Reports, Science and Social Sciences Editions (Thomson Reuters), just 5\% were OA.

Björk, Roos, and Lauri (2008) estimated that in 2006, the total number of articles published was approximately $1,350,000$. Of this number, $4.6 \%$ became immediately openly available, and an additional $3.5 \%$ were so after an embargo period of typically 1 year. Furthermore, usable copies of $11.3 \%$ could be found in subject-specific institutional repositories or on the home pages of the authors. Thus, the total OA was $19.4 \%$.

In a more recent article, Björk et al. (2010) looked at the availability of OA articles, whether published in open-access journals (gold road) or from repositories or websites (green road) over a sample stratified by disciplines, of 1,837 articles from the Year 2008 selected from the SCOPUS database. The availability of OA articles was $20.4 \%$ (8.5\% in OA journals, $11.9 \%$ in repositories and websites). A breakdown by discipline revealed that in medicine, medicine-related areas and biochemistry and molecular biology, the gold road surpasses the green one-in fact, nearly doubling the figures (14 vs. $8 \%, 14$ vs. $6 \%$, and 11 vs. $5 \%$, respectively). Yet, in other thematic areas, the situation is reversed: Noteworthy for their use of auto-archiving are the earth and environmental sciences (25.9\%); physics and astronomy (20.5\%), the social sciences, arts and humanities (17.9\%), and mathematics (17.5\%).

Still other studies have described the influence of OA on citation. A pioneer in this direction is Lawrence (2001), who showed that the greatest percentage of citation of computer science articles corresponded to work freely available on the Internet, to a much greater extent than works with limited access. Later studies arrived at the same finding in fields such as physics (Hajjem et al., 2005), astrophysics (Kurtz et al., 2005), ecology, applied mathematics, sociology, and economics (Norris et al., 2008). A recent article in Molecules covering the journals of Molecular Diversity Preservation International (MDPI) announced a steady increase in their impact factors throughout 2009 and the inclusion of some in the Thomson Reuters databases as a result of their OA policy established at the beginning of 2007 (Rordorf, 2010).

Still other studies have found that OA yields no benefits regarding citation in physics-condensed matter (Moed, 2007), conservation biology (Calver \& Bradley, 2010), and certain other fields. Two recent review articles by Swan (2010) and by Wagner (2010) clearly presented contrasting results.

Eysenbach (2006) affirmed that OA holds great potential for accelerating the acknowledgment and diffusion of research findings, but that its effects on the impact of contributions is quite a different and controversial matter. A similar conclusion was found by Moed (2007), who underlined that OA has immediate effects on citation due to the prompt availability of online articles, not because of OA, per se. Davis et al. (2008) found that OA articles reach a greater audience and show a higher number of downloads than do those accessed by subscription, yet this did not entail an increase in citation the year after publication; in other words, OA citation may be due to other causes such as an increase in readership not stemming from the academic world and who therefore do not cite. It may be that OA use is highly influenced by the website interface of the publishers or their full-text access policy (Davis \& Price, 2006), or that OA use simply depends on whether an article is hung on the webpage of a more prestigious publishing company or on personal or institutional pages, as stressed by Eysenbach (2006). Bessemer (2006) and Turk (2008) disputed the methodology used to compute 
citations, arguing that a reasonable period of time should elapse to accurately evaluate impact and avoid short-term, categorical analyses.

Using different factors, Craig, Plume, McVeigh, Pringle, and Amin (2007) also noted methodological difficulties in evaluating the impact of OA. First, citation may be conditioned by the age of articles and the effects of accumulated citation received by the older articles. Second, when comparisons are made grouping journals of different geographic sources and situations with respect to OA, the results can be erratic. Third, not all disciplines use journals as the main channels of communication of research findings, and they may have different citation behaviors. Harnad (2007) reported four independent factors that contribute to greater citation in the field of biomedicine, ranging from the time since publication, the impact factor of the journal in which the article appears, the number of authors, and OA status. Yet, the results of a recent study based on a sample of 27,197 articles published in 1,984 journals in the period 2002 to 2006 showed that the advantage of OA over citation is independent of factors such as age of the article; the journal's impact factor; number of authors, references, or pages; country of the institution; and the type of article; the advantage is causal and depends on the quality of the articles (Gargouri et al., 2010). Eysenbach (2006), taking into account the number of authors, country of origin, and discipline, found OA articles to be cited twice as much. However, when a journal wields great prestige, such as the Proceedings of the National Academy of Sciences, USA, the results cannot necessarily be extrapolated to other journals. In short, journal prestige still stands as a quality brand name for the contents of an article, and persists as one key behind citation.

\section{Objectives and Hypothesis}

This research is intended to complement previous studies by incorporating a new analytical approach toward the OA movement, from the perspective of the economic model of the journals registered in SCOPUS, as well as OA influence on visibility, in view of diverse geographic and thematic distributions. The article analyzes journals according to their formal OA status; it does not focus on comparing actual freely accessible papers with toll-access papers.

As specific goals, we set forth to:

- Determine the coverage of the SCOPUS journals with regard to the OA movement (gold road and green road), on the global level as well as by disciplinary groups.

- Identify the distribution of journals by geographic region to corroborate if they largely coincide with either the green or gold road.

- Assess the influence of the OA movement in citation behavior in the different scientific disciplines and geographic regions, from impact indicators of journals according to their economic model.

Thus, the present study explores the following hypotheses:

H1: There is a stronger gold road in the social sciences and humanities.
H2: There is a greater proportion of gold road journals in emerging economic regions.

H3: These journals are not the most relevant and are, for the most part, from the last quartile (Q4).

\section{Material and Methods}

\section{Data Sources}

We based our study on four key data sources:

- The list of titles in SCOPUS as of April 2010, on their official webpage (last retrieved from http://www.info.scopus.com/ documents/files/scopus-training/resourcelibrary/xls/title_list .xls)

This list gives all publications registered in the database $(n=27,861)$. Of these, we selected the journals active in the categories "Journal" and "Trade Journal." We excluded inactive titles or documents of the type "Book Series" or "Conference Proceedings." Our source corpus then amounted to 17,284 journals. We should add that when the list was downloaded, the page "Content Coverage of Scopus" (http:// info.scopus.com/scopus-in-detail/facts/) indicated coverage of 16,500 journals, a discrepancy that might be explained by the delay between updating the source and the information actually published on the website. From this source, we took editorial data regarding each journal: title, ISSN, publisher, country where published, and thematic classification.

- The DOAJ of Lund University Libraries (http://www.doaj. org/), a repertory of international reference in the register of gold road journals, which when consulted (June 2010) harbored a total of 5,138 titles. This directory covers free, full-text, quality-controlled scientific and scholarly journals. DOAJ defines OA journals as journals that use a funding model that does not charge readers or their institutions for access.

- The webpage of project RoMEO, developed by the SHERPA group of the University of Nottingham (www.sherpa.ac.uk/ romeo.php), self-archiving policies established by more than 700 academic/scientific publishers worldwide. The 10 publishers who adhere to the green route with the largest number of journals in SCOPUS are Elsevier, Blackwell, Springer, Sage, Taylor \& Francis, John Wiley \& Sons, Lippincott Williams \& Wilkins, Oxford University Press, Emerald, and Bentham Science.

- SCImago Journal \& Country Rank (http://www.scimagojr. com/), developed by the SCImago Group (http://www. scimago.es), which publishes indicators of output, visibility, and collaboration of the journals included in SCOPUS.

\section{Levels of Analysis}

For thematic analysis, we resorted to the scheme of Subject Area Categories by SCOPUS (http://help.scopus.com/robo/ projects/schelp/h_subject_categories.htm), which classifies journals in just four broad areas: Physical Sciences, Health Sciences, Life Sciences, and Social Sciences. Then, to facilitate comparison, we adopted the specific thematic groups proposed by Björk et al. (2010).

Geographic analysis called for grouping the journals' countries of origin into six regions: Europe, North America, Asia, Latin America and the Caribbean (LAC), Oceania, and Africa. 


\section{Preparation of the Sources and Crossing Data}

Identification and inventory of the gold road journals. We compared the lists of Sources A and B with reference to the journal ISSN to derive a list of SCOPUS journals that also were registered in the DOAJ; that is, the number of gold road SCOPUS journals. Although the Source A list includes a column with data about the economic model adopted by each journal (OA vs. No-OA), early ventures made us aware that this information was not up to date, as the number of OA journals from Source A located within Source B is vastly greater than that reflected by the listing.

Identification and inventory of the green road journals. Based on information from the webpage of the RoMEO Project by SHERPA, we created Source C, in which each publishing company is identified with a color that symbolizes the type of policy adopted regarding self-archive. A green tone indicates that the authors can self-archive the preprint, the postprint, or the PDF version of the editor. The blue tone represents publishers that allow for self-archiving of the postprint (and post-peer-reviewed) versions or the editor's PDF version. The yellow tone indicates permission for self-file of the preprint versions, before peer review. White represents the editors who do not permit self-archiving, or that no information is available. The former three groups, then, are the editors adhering to the OA movement via the green route.

If we compare the list of editors from Sources C and A and if we normalize their names to allow us to cross data, each editor of Source $\mathrm{C}$ can be associated with one or more journals from Source A, and we identify the Source A journals associated with the colors that symbolize each type of publisher from Source C. Using these data, we can calculate the total number of journals that permit some form of self-archiving and which we include in the green road group.

Identification and inventory of the non-OA journals. Having finalized the first and second processes, we configure the group of non-OA journals, gathering up the set of titles not on the gold or the green road. Note also that SHERPA has explicit conditions of some 700 publishers. This means that for quite a large share of the journals in SCOPUS, especially publishers publishing only one journal and particularly publishers outside of the English language, there is no available information. However, there are many small journals that do not even have copyright information on their sites and that do not require authors to sign away the copyright. Hence, there is a risk in interpreting the non-OA journals.

Calculating the impact indicators. We consulted the total list of journals included in the SJR. We selected the Year 2008 as the criterion of selection for calculating the indicators, and downloaded the data in a grid (Source D). Then we compared the journals from Sources A and D and normalized the titles that presented variations in their denomination. In the SJR, we found some journals that were not on the SCOPUS list, and vice versa. Considering the fact that this could be due to some delay in updating the sources, we opted to calculate indicators of impact only for the journals present in Source A as the predominating source of our study. We placed the journals into the groups identified in Stages 1 through 3: gold road, green road, and non-OA. For each group, we calculated the number and percentage of journals and the average value of the SJR indicator and of the citations per document for a chronological window of 2 years (Cites/Doc. (2 years). The indicator Cites/Doc is the mean number of citations per document in 2 years. To calculate this indicator, we noted the number of citations received in the 2 previous years and the number of documents published in the year selected (SCImago, 2007). We calculated a Cites/Doc ratio for each journal separately and then calculated the mean ratio over all journals. The SJR indicator expresses the number of links that a journal receives through the weighted citation of its documents in relation to the number of documents published per year for each publication. Weighting of citations was done in terms of those received by the citing publication. The SJR indicator considers journal impact in terms of the citations received, also taking into account the quality of the citing journals (González-Pereira, Guerrero-Bote, \& Moya-Anegón, 2010). These indicators were calculated for the entire volume of journals from each group, and then again for the groupings by theme or geographic region.

Analysis. Analysis was global, by theme and by geographic aggregates, depending on the economic model adopted (gold road, green road, and non-OA) to compare journal distributions. To test our first hypothesis, we used the chi-square test to determine significant differences in the different disciplinary groups and regions with regard to the OA movement. Visibility of the groups of journals was compared according to the underlying economic model, and visibility of the journals was analyzed, grouping them by quartiles, on the basis of the SJR indicator from the source SCImago SJR.

\section{Results}

\section{SCOPUS Coverage in Relation to the Economic Model of the Journals}

From a general standpoint, SCOPUS journal ascription to the OA movement amounts to $41 \%$ (9\% gold road journals, $32 \%$ green road journals (Figure 1). Despite the limitations of indicators regarding visibility and sets of journals in heterogeneous disciplinary domains, it is fairly clear that in general the journals that comply with self-archive receive, on average, more citations per document than do those published in OA journals (gold road) or traditional pay-to-subscribe journals (non-OA), which present no relevant or significant differences in the values for this indicator.

These results converge with those of other studies (Gargouri et al., 2010, Harnard et al., 2004; Moed, 2007); as we mentioned earlier, one possible explanation is that wellconsolidated journals of great prestige, such as Nature, Cell, or Science, are not integrated in the OA movement because they wield very high visibility and because subscriptions are economically beneficial to them. OA might afford some 


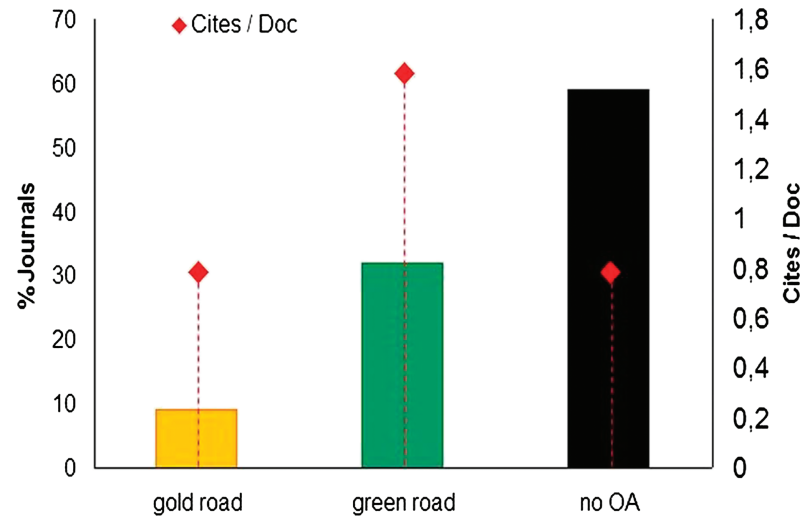

FIG. 1. Distribution of the journals according to the open access movement. [Color figure can be viewed in the online issue, which is available at wileyonlinelibrary.com.]

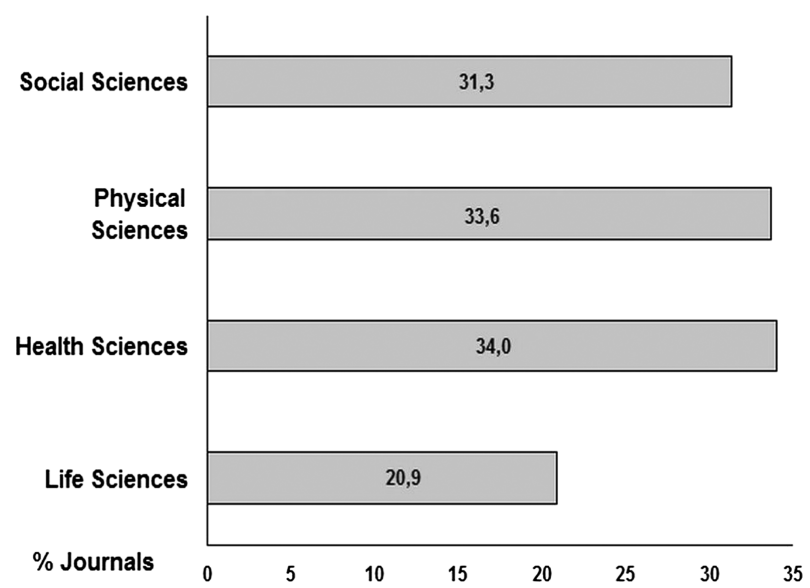

FIG. 2. Thematic distribution of the journals in SCOPUS.

advantage along the green road, but certainly not on the gold route.

\section{Thematic Distribution of Journals}

The thematic distribution of SCOPUS journals is quite well-balanced. The main thematic divisions, Health Sciences, Physical Sciences, and Social Sciences, share presences near $30 \%$, Life Sciences lagging close being with 20\% (Figure 2). Percentages do not sum to 100 due to multiple assignment of journals to main fields. This comes as somewhat of a surprise, as bibliographic databases-first, the WoS and later, Scopus - are often accused of lacking coverage in the social sciences not only because of well-known different publication habits but also because of the lack of proportion in their coverage with respect to other fields. The importance of journals in the social sciences owes mainly to the incorporation of journals from the European Science Foundation's European Reference Index for Humanities since June 2009. This means that we are dealing with a multidisciplinary, international tool and with an expanding area of social studies and humanities, which will permit us to branch out and revise earlier studies in which the thematic coverage in this direction was seen as deficient (Moya-Anegón et al., 2007).

When we analyze journal distribution of the SCOPUS journals according to the economic model for each one of the four major areas (see Table 1), it becomes apparent that OA journals are not predominant in all fields. The green road is clearly the strongest modality of OA, and in relative terms, the distribution is quite similar in all fields. For the gold road, in contrast, Life Science and Health Sciences clearly dominate over Physical Sciences and Social Sciences. At this point, note that the results of our study relate to the number of journals, not to the number of documents published in these journals. However, we present the average number of papers per journal for the Year 2008 at the level of main fields and observe that there are differences among research fields. Nonetheless, green journals have the highest average number of items in all fields. Note that the percentages of journals according to the economic model in Table 1 are calculated on the universe of journals in each field.

Now, if we take as point of reference the thematic distribution of the gold road journals, comparing sources SCOPUS and the DOAJ, we see our first hypothesis partly confirmed. From the perspective of the international directory DOAJ, the Social Sciences have the greatest percentage (39\%) of gold road journals, ahead of Health Sciences (24\%), Physical Sciences (20\%), and Life Sciences (14\%). In contrast, SCOPUS shows a lesser presence of the gold road in all the fields, reaching just $12 \%$ of the journals in Life Sciences and in Health Sciences (Table 2). Note that the comparison between the DOAJ and SCOPUS is made over the universe of gold road journals (DOAJ: $n=5,138$; SCOPUS: $n=1,567$ ).

TABLE 1. Thematic distribution of the journals in SCOPUS by economic model.

\begin{tabular}{|c|c|c|c|c|c|c|c|c|c|c|}
\hline \multirow[b]{2}{*}{ Main fields } & \multicolumn{3}{|c|}{ Gold road } & \multicolumn{3}{|c|}{ Green road } & \multicolumn{3}{|c|}{ No-OA } & \multirow[b]{2}{*}{$\begin{array}{l}\text { Total } \\
\text { journals by } \\
\text { main fields }\end{array}$} \\
\hline & $\begin{array}{c}\text { No. of } \\
\text { journals }\end{array}$ & $\begin{array}{c}\text { Journals } \\
(\%)\end{array}$ & $\begin{array}{c}\text { Average } \\
\text { no. of papers } \\
\text { per journal } \\
(2008)\end{array}$ & $\begin{array}{c}\text { No. of } \\
\text { journals }\end{array}$ & $\begin{array}{c}\text { Journals } \\
(\%)\end{array}$ & $\begin{array}{c}\text { Average } \\
\text { no. of papers } \\
\text { per journal } \\
(2008)\end{array}$ & $\begin{array}{c}\text { No. of } \\
\text { journals }\end{array}$ & $\begin{array}{c}\text { Journals } \\
(\%)\end{array}$ & $\begin{array}{c}\text { Average } \\
\text { no. of papers } \\
\text { per journal } \\
(2008)\end{array}$ & \\
\hline Social Sciences & 290 & 5.4 & 25.6 & 1,861 & 34.4 & 41.7 & 3,253 & 60.2 & 34.8 & 5,404 \\
\hline Physical Sciences & 475 & 8.2 & 77.4 & 1,845 & 31.7 & 155.4 & 3,497 & 60.1 & 116.1 & 5,817 \\
\hline Health Sciences & 668 & 11.4 & 80.0 & 1,852 & 31.6 & 129.8 & 3,349 & 57.1 & 94.8 & 5,869 \\
\hline Life Sciences & 455 & 12.6 & 79.4 & 1,297 & 35.9 & 145.4 & 1,859 & 51.5 & 108.8 & 3,611 \\
\hline
\end{tabular}


TABLE 2. Thematic distribution of the gold road journals in the Directory of Open Access Journals (DOAJ).

\begin{tabular}{lrr}
\hline & \multicolumn{2}{c}{ DOAJ } \\
\cline { 2 - 3 } Main field & No. of journals & Journals (\%) \\
\hline Social Sciences & 2,020 & 39.31 \\
Health Sciences & 1,253 & 24.39 \\
Physical Sciences & 1,056 & 20.55 \\
Life Sciences & 731 & 14.23 \\
Multisdisciplinary Sciences & 78 & 1.52 \\
Total & 5,138 & 100.00 \\
\hline
\end{tabular}

If we descend a level and segregate these fields into more specific thematic areas, we find that the percentage of journals in Social Sciences, Arts and Humanities (SSA\&H) comprises $31 \%$ of the total database. This figure lies above the rest, including Medicine.

Another strong point of SCOPUS is its coverage in Engineering and Technologies, where it by far outdoes the percentage of journals in Ulrichs' Web (Moya-Anegón et al., 2007). The results show that over $18 \%$ of the journals belong to this category. At the other extreme, Physics and Astronomy take in just under $5 \%$ of the journals, and Chemistry and Mathematic are over 5\%.

This leads us to the question of in which thematic categories are the OA journals most concentrated, regardless of whether they belong to the gold or the green road? Figure 3 shows the breakdown by economic model and category to the left; to the right, the percentage of journals of each thematic area in the database are presented. Percentages do not sum to 100 due to multiple assignment of journals to main fields.

At first glance, one can see a fairly balanced distribution among the disciplinary groups with respect to journal access.
The percentage that ascribes to OA is near $50 \%$ in most cases. The discipline showing the best adhesion to OA is Biochemistry, Genetics and Molecular Biology, with over $52 \%$ of the journals, followed at some distance by Mathematics, Physics and Astronomy, and Areas related to Medicine. At the other extreme, the least adherence is seen for Engineering, with $36 \%$, followed by Social Sciences, Arts and Humanities, and then Earth and Environmental Sciences. In all the disciplinary groups, the green road widely surpasses the percentage of gold road access, with a difference close to $30 \%$ in nearly all cases. In Medicine, Earth and Environmental Sciences, and Engineering, the differences are less remarkable $(20,16$, and $24 \%$, respectively). In the first two cases, they coincide with the discipline having a greater percentage of journals in the gold route (12\%); contrariwise, in the latter case, it is the field with the least percentage of journals (40.8\%) adhering to the OA movement. We confirm that among the disciplinary groups, there are significant differences with regard to the economic model of the journals, $\theta^{2}(16)=392.6$, $p<0.001$.

By weighting the percentage of journals according to the economic model with respect to the total percentage of journals in the database in each thematic category, we can see that the gold road predominates in Medicine, followed by Earth and Environmental Sciences, and then SSA\&H (Figure 4).

The surprising finding by Björk et al. (2010)—that gold road articles surpass by far the green road ones in Medicine, Areas Related to Medicine, and Biochemistry, Genetics and Molecular Biology_was not seen in our study, where the green road prevails in all disciplinary groups. This finding reveals that from the standpoint of the journals themselves, the green road has great potential for expansion that is perhaps not being taken advantage of by the authors. This is a finding

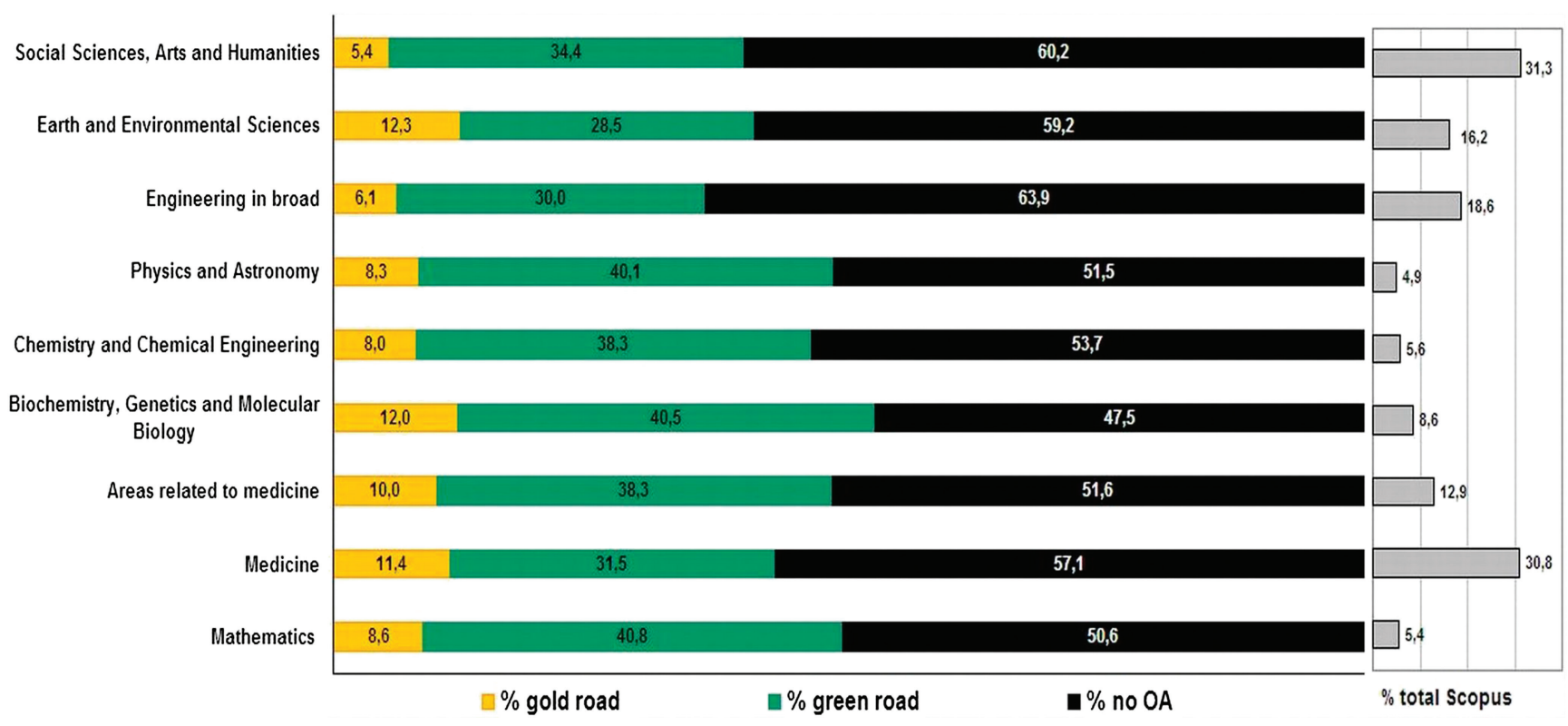

FIG. 3. Percentage-wise distribution of gold road, green road, and non-OA journals by thematic category. [Color figure can be viewed in the online issue, which is available at wileyonlinelibrary.com.] 


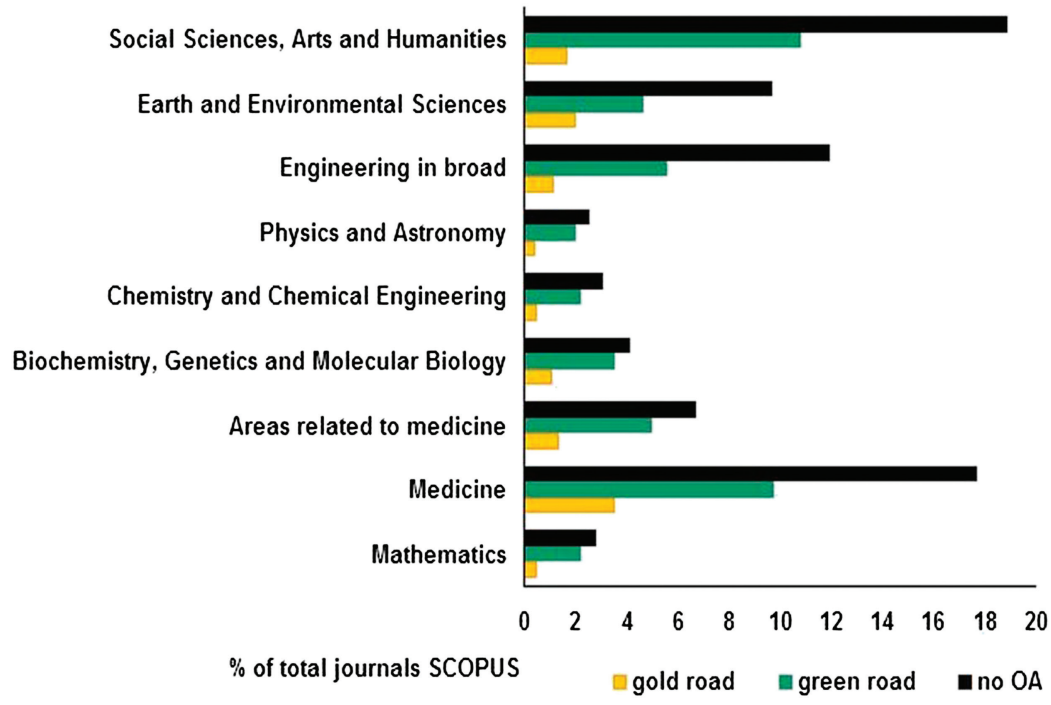

FIG. 4. Percentage of gold road, green road, and non-OA journals with respect to total SCOPUS journals by thematic category. [Color figure can be viewed in the online issue, which is available at wileyonlinelibrary.com.]

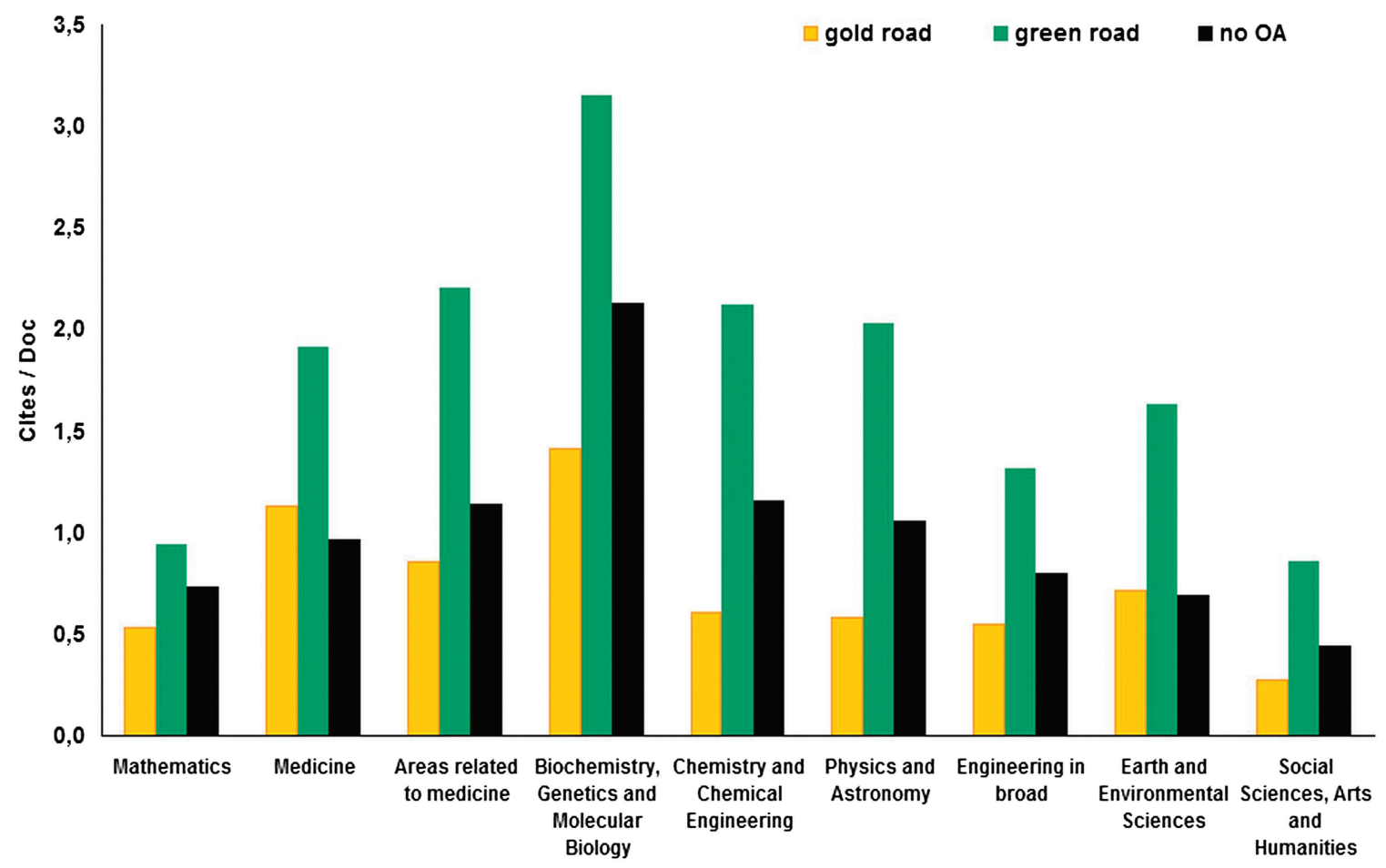

FIG. 5. Cites per document of journals: gold road, green road, and non-OA. [Color figure can be viewed in the online issue, which is available at wileyonlinelibrary.com.]

of relevance for authors as well as for the persons responsible for repositories and institutional policies.

\section{Visibility}

Figures 5 and 6 show the average visibility achieved by the journals in each thematic category according to the economic model, using the indicators Cites/Doc (2 years) and SJR. These two units of measure give information on different facets of visibility/impact/use that have to do with popularity and prestige, and they are highly correlated (González-Pereira et al., 2010). The SJR indicator considers journal impact in terms of the citations received, also taking into account the quality of the citing journals. This has implications beyond popularity (i.e., citations per document) and the use of the information in question. Accounting for the origin of citations grants an added value to appraisal of its use and has much to do with the prestige of the 


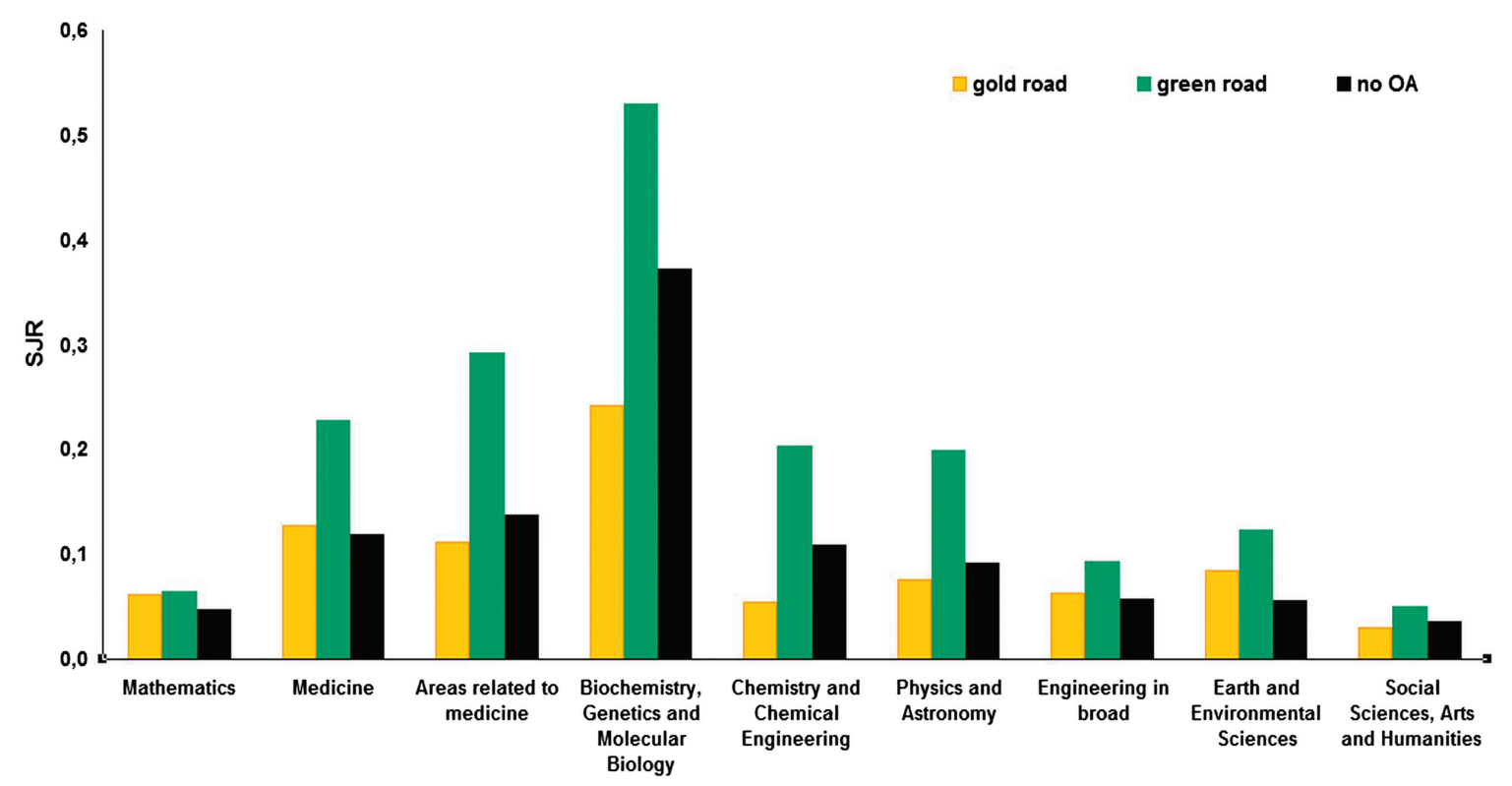

FIG. 6. SJR average of the journals, according to the economic model. [Color figure can be viewed in the online issue, which is available at wileyonlinelibrary.com.]

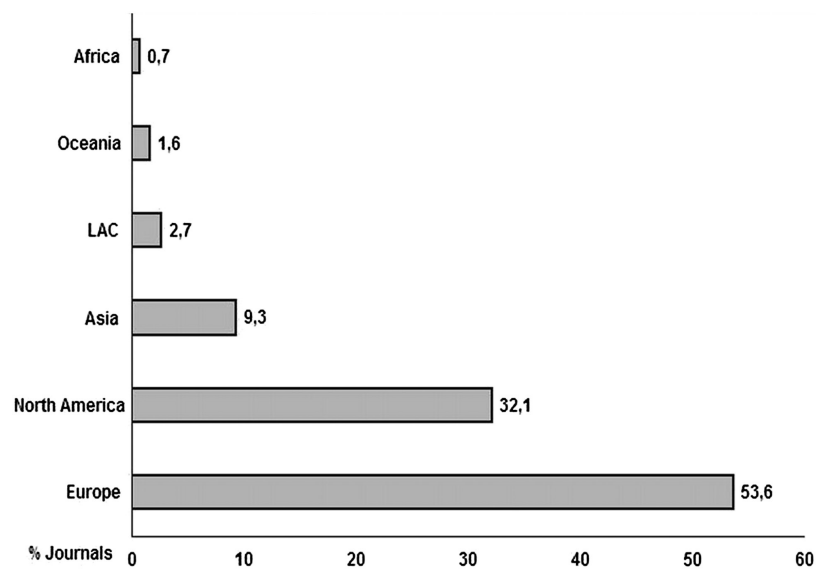

FIG. 7. Distribution of the journals by geographic region.

journal, not just the citation-based indicators. Due to the variability of impacts among disciplines, the SJR is not directly comparable for the different thematic areas. Figures 7 and 8 reveal the differences in impact between gold road, green road, and non-OA journals within each disciplinary grouping.

Given these considerations, we may say that in terms of citation per document or popularity in all disciplinary groups, the green road journals achieve the highest values, followed by the non-OA journals, and then the gold road journals, except in Medicine where they are slightly higher than the average cites per document of the non-OA journals. In Earth and Environmental Sciences, the visibility of the gold road journals and the non-OA journals is basically the same. Also note that the greatest number of citations per document in the green route is seen in the category Biochemistry, Genetics and Molecular Biology, followed by Areas Related to Medicine, Chemistry and Chemical Engineering, and Physics and Astronomy; the least cited journals are SSA\&H and Mathematics (Figure 5).

Utilizing the SJR indicator, we observe the same phenomenon: The green road journals are the most prestigious. Although there are thematic areas in which the differences among the three groups are minimal-the case of Mathematics SSA\&H, for example - there is hardly any difference in visibility and prestige between the gold road and the non-OA journals. Yet, note that Engineering in broad, and Earth and Environmental Science house gold road journals with higher prestige than do the non-OA ones. We therefore agree with Harnad et al. (2008) in that the green route is the only option leading to $100 \% \mathrm{OA}$ in the future.

\section{Coverage of Journals in SCOPUS by Geographic Region}

Figure 7 displays the percentage-wise distribution of SCOPUS journals by geographic region of origin. Europe produces $54 \%$, and North America $32 \%$. These are followed, at some distance, by Asia (9\%), LAC with $2.7 \%$, Oceania (1.6\%), and Africa (0.7\%). This distribution is similar to the one observed regarding scientific output on the worldwide level: Three regions concentrate over $80 \%$ of world production (Moya-Anegón \& Chinchilla-Rodríguez, 2009).

When the regional distribution is further broken down by economic model (Figure 8), the differences between Europe and North America are less pronounced. Now these are the regions with a greater adhesion of green road access, representing 38 and 35\%, respectively. The pattern seen in LAC is very distinct: Seventy-four percent of the journals of this region included in SCOPUS are gold road ones, and there are practically no green road journals registered. Excepting LAC, there is a high percentage of non-OA journals overall.

We also note three well-differentiated groups of regions of the scientific world; the consolidated, the peripherical, and the 


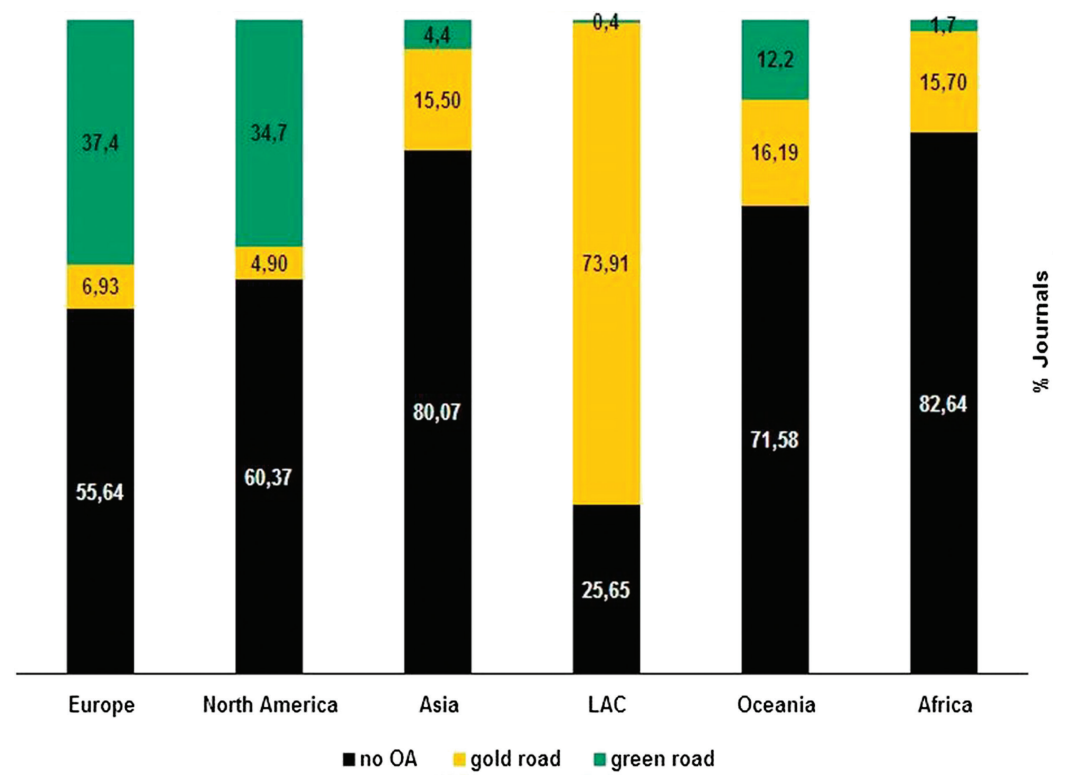

FIG. 8. Distribution of the journals according to economic model and geographic region. [Color figure can be viewed in the online issue, which is available at wileyonlinelibrary.com.]

emerging, in which more than $35 \%$ of the journals allow for self-archiving. The regions of Europe (The Netherlands and the United Kingdom) and of the United States ( 38 and 35\%, respectively) represent $73 \%$ of journals included in SCOPUS, for Europe by the publishers Elsevier and Springer as evidenced in other studies (Moya-Anegón et al., 2007); regions that are traditionally peripheral (from the standpoint of scientific output and their editorial presence in major databases) with very little green road presence, such as Africa and LAC. There also are emerging regions, Asia and Oceania, where over $15 \%$ of the journals are gold road ones, and the green route percentage is very different.

The case of LAC is remarkable. One reason could be that publishers in this region do not establish clear policies regarding self-archiving. Moreover, they feature some unusual initiatives such as the projects Scientific Electronic Library Online (SciELO; www.scielo.org) and the Red de Revistas Científicas de América Latina y el Caribe, España y Portugal (redalyc; redalyc.uaemex.mx/), digital libraries that offer full-text access to journal articles, but do not have all the characteristics of repositories. In other words, there are certain ways in which this region is fomenting the green road, but unlike the way it is developing in the rest of the world. But what does it tell us? Despite these projects to create repositories and digital libraries, a large percentage of journals of SciELO and Redalyc are not included in the DOAJ (because are not gold road), and its publishers are not included in SHERPA/RoMEO. So, what are the implications for the data presented in this article? These journals are not covered by the OA reference sources worldwide. Therefore, the recommendation is that the publishers of journals of the LAC should establish clear policies regarding self-archiving and the successful integration of international standards that account for the policies adopted by publishers in relation to OA in world.
Further, the authors believe that given the particularities of the LAC region, it is necessary to study the influence of OA from the analysis of regional sources indicated.

The results shown in Figure 8 do not account for important factors bearing on visibility, such as the different thematic specialization of each region. Europe and North America exhibit more or less balanced distributions of the journals ascribing to some form of OA (gold plus green road) against the non-self-archive journals. In all four areas, the percentage of green road journals lies in the range of 35 to $46 \%$, except Physical Sciences within North America, where the percentage is somewhat reduced (30\%). Is this due to the large U.S. societies such as the American Physical Society (APS) and the American Chemical Society (ACS)? What about IEEE? Although we have no intention to delve into this issue, note that there are seven green road journals from APS while ACS has no journals in SCOPUS. In future research, it could be interesting to analyze the role of large societies and publishers in the OA phenomenon. The gold road journals are under $10 \%$ in all cases.

Asia and Africa present similar patterns insofar as the considerable proportion of non-OA journals, over $70 \%$ in all cases; the gold road journals take second place. In Asia, outstanding areas are Life Sciences and Health Sciences, in which the gold road figure is nearly $25 \%$. In Africa, this OA mode is noteworthy in the case of Life Sciences and in Physical Sciences, with 28 and 21\%, respectively.

Deserving special mention is Oceania: Even though most of the journals it publishes are non-OA, the rest are essentially half gold or half green. The main distinction would be in the area of Health Sciences, where the gold road figure is twice that of the green road figure ( 27 vs. $13 \%$ ).

LAC marks the exception to the rule. Aside from the unexpected finding that most of its journals are gold road ones, 
TABLE 3. Chi-square test of the distribution of journals according to geographic region and thematic area.

\begin{tabular}{lc}
\hline Region & $\theta^{2}$ \\
\hline Europe & 188.9 \\
North America & 56.7 \\
Asia & 111.4 \\
LAC & n.a. \\
Oceania & 8.0 \\
Africa & n.a. \\
\hline
\end{tabular}

Note. n.a. $=$ not applicable.

we also discern that this holds true in all four areas in a quite balanced way, although Social Sciences stands out with $81 \%$ of the journals. Also note that there is absolutely no green road representation in Life Sciences or Health Sciences, and it is very scanty in the other two areas.

To determine if there are significant differences in the economic models adopted by each geographic region with respect to the thematic areas covered by the journals, we calculated the chi-square value (Table 3$)$. The results, $\theta^{2}(6)$, $p<0.001$, confirm that the regions Europe, North America, and Asia exhibit significant differences with regard to the model adopted by the journals in each thematic area; no significant differences were found for Oceania. For the regions of LAC and Africa, we were not able to calculate this indicator because the expected frequencies were under 5 , and statistically it is not worth calculating because they are not relevant.

An initial approach to regional visibility according to the economic model of the journal sheds light on some significant details that differentiate regions. Despite having similar figures for green road journals, visibility is much greater in Europe than it is in North America, and the differences regarding the gold road are even greater. In Oceania, the non-OA journals surpass the gold road ones in popularity whereas in Africa, the gold road is higher in visibility than are the non-OA journals and the green road journals. A similar trend can be seen for LAC, yet involving only the non-OA journals, as there is no visibility at all of green road publications (Figure 9).

The mean visibility as measured by the SJR indicator (Figure 10) leads us to affirm that in Europe and North America, the green road attains higher average impact than do the gold road or the non-OA journals in all four thematic areas. Also note that in North America, the impact reached by the green road journals in Health Sciences is similar to that seen for non-OA publications.

In the other regions, the mean impact of the journals is much lower than that in Europe and North America. The green road exists in terms of impact in Asia and Oceania only in the areas of Life Sciences and Physical Sciences. Furthermore, the green road has more impact than does the gold road in Oceania, within the area Physical Sciences.

In LAC, the gold road surpasses, on average, the impact of the non-OA journals in Health Sciences alone; but not in Physical Sciences, where the greatest relative impact corresponds to the non-OA journals. In Life Sciences, there is a draw; in Social Sciences, we find only gold road journals, with no impact values obtained for the other two models. Then again, note that this region produces virtually no green road journals, and in the two areas where there is indeed some greenery (Physical Sciences and Social Sciences), there is no impact from the standpoint of the SJR indicator for 2008.

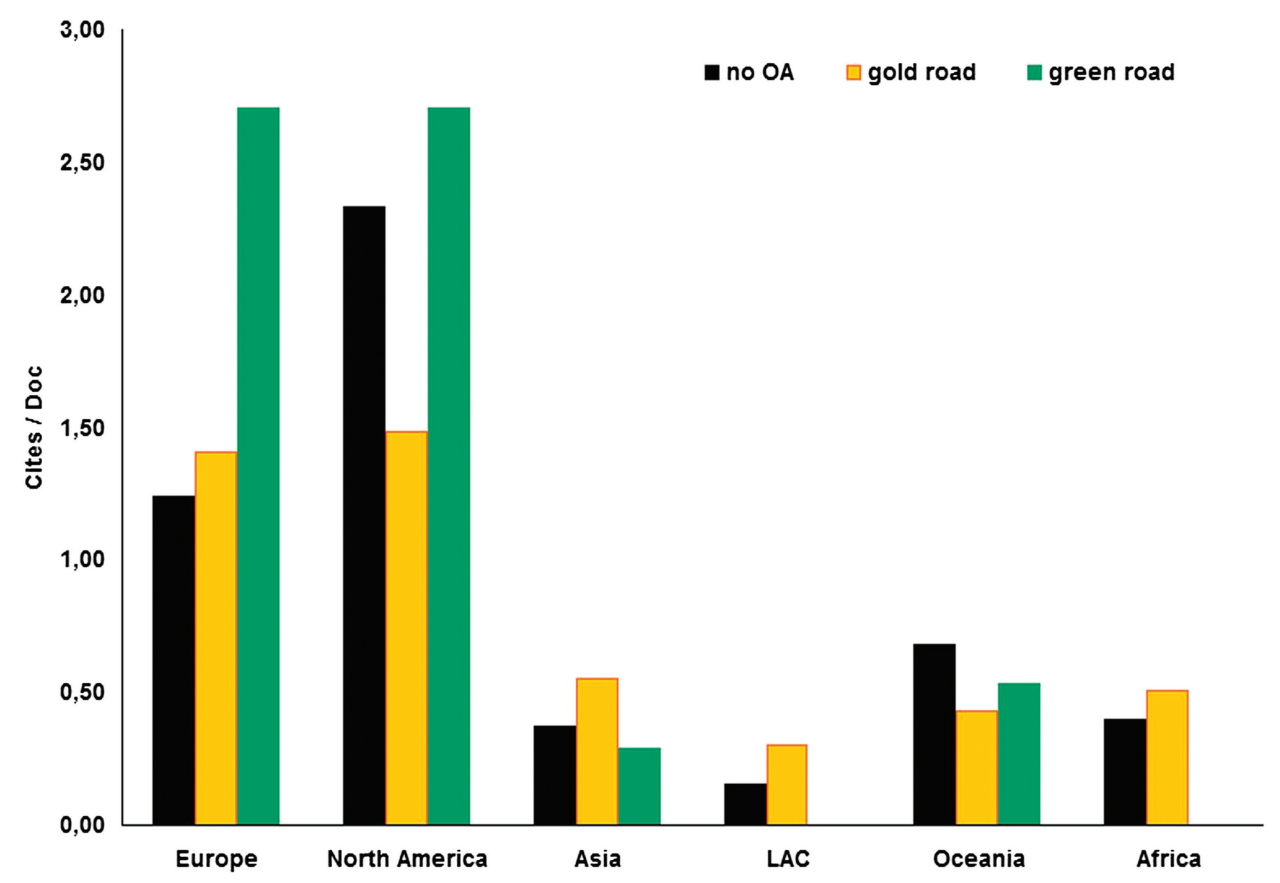

FIG. 9. Average cites per document by region, according to the economic model of the journals. [Color figure can be viewed in the online issue, which is available at wileyonlinelibrary.com.] 


\begin{tabular}{|c|c|c|c|c|c|c|c|}
\hline $\begin{array}{l}0,50 \\
0,45\end{array}$ & \multirow{9}{*}{\multicolumn{2}{|c|}{$\begin{array}{l}\square \text { no } O A \\
\square \text { gold road } \\
\text { green road }\end{array}$}} & \multicolumn{5}{|c|}{$\begin{array}{l}\text { TABLE 4. Percentage-wise distribution of gold-route journals in quartiles } \\
\text { according to their visibility, by geographic region. }\end{array}$} \\
\hline 0,40 & & & Region & Q1 & Q2 & Q3 & Q4 \\
\hline 0,35 & & & & & & & \\
\hline 0,30 & & & Europe & 0.7 & 4.4 & 11.7 & 25.3 \\
\hline 0,25 & & & North America & 0.8 & 1.5 & 3.5 & 12.5 \\
\hline 0,20 & & & Asia & 0.0 & 0.3 & 2.4 & 12.3 \\
\hline 0,15 & & & LAC & 0.0 & 0.0 & 0.8 & 20.9 \\
\hline 0,10 & & & Oceania & 0.0 & 0.0 & 0.3 & 1.5 \\
\hline 0.05 & & & Africa & 0.0 & 0.0 & 0.0 & 1.0 \\
\hline
\end{tabular}

Finally, we analyzed the gold road journal distribution by geographic region, into quartiles, based on the SJR values. The results support our working hypothesis in that the gold road journals of the peripheral and emerging countries belong to Q4 (Table 4). Furthermore, we can state that this also is true for Europe and North America, and conclude that the gold road offers the least visibility in any region.

What is clear from the overall panorama is that the best positions in terms of visibility are held by the traditional journals that have explicit policies in favor of some form of self-archive in repositories. It is likewise manifest that the advantages of OA upon visibility are mainly due to the green road, not the gold one, and that Europe together with North America are at the forefront as the regions with greater percentages of green road journals, with which they harvest greater impact.

In contrast, in the peripheral regions where the green road is virtually nonexistent and the gold road is relatively abundant, it did not achieve higher levels of impact than did the non-OA journals. The exception is Health Sciences in LAC, due to the strong promotion of OA by means of the initiatives and projects mentioned earlier, and in the case of Brazil, BIREME/OPAS/OMS and other such intergovernmental bodies.

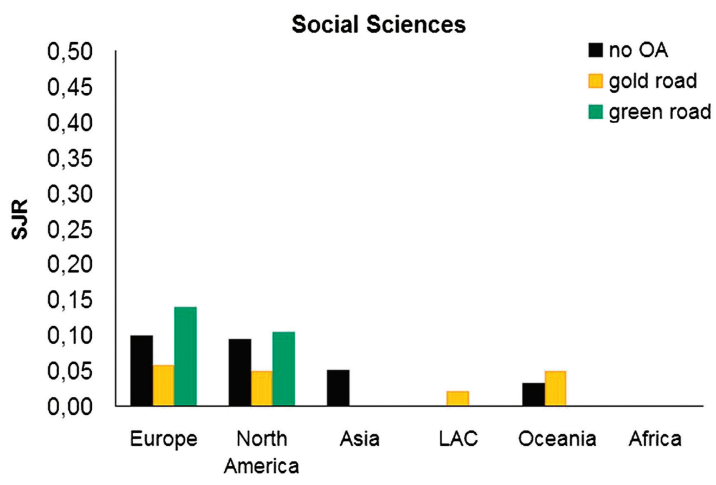

FIG. 10. SJR averages by thematic area and geographic region. [Color figure can be viewed in the online issue, which is available at wileyonlinelibrary.com.]

Perhaps this is due to the recent incorporation of these in the database, and we should wait a few years for them to begin to make these data available to the general public, as has occurred with the Journal Citation Reports of Thomson Reuters.

\section{Discussion and Conclusions}

SCOPUS offers a thematic coverage of journals that can be said to have a good balance in general terms. It has become the international multidisciplinary source of data with the greatest percentage of journals in the SSA\&H, besides Engineering and Technologies, overcoming a limitation of bibliographic databases in the past. However, there is still room for improvement in aspects that may affect bibliometric analysis, such as comprehensive coverage of journals and inclusion of the countries of affiliation of all authors. Regarding OA, it provides more homogeneous coverage among the thematic areas than does the other outstanding source of information, the DOAJ.

The percentage of journals in some form adhering to the self-archiving trend in SCOPUS ranges from the 50\% we obtained for Biochemistry, Genetics and Molecular Biology and the 36\% seen in SSA\&H. In all the disciplinary groups, the presence of green road journals widely surpassed the percentage of gold road publications. 
The peripheral and emerging regions have greater proportions of gold road texts, and publication in green journals is almost inexistent. In broader terms, a possible explanation could be that scientists-as-readers in peripheral countries are served equally well by $\mathrm{OA}$, as is the case for scientists in poor countries, provided that the Internet connections are available with the rise of OA. This is the argument most often put forth to justify creating new OA journals or archiving peer-reviewed articles in suitable repositories. On the other hand, scientists-as-authors may discover that getting an article accepted in an OA journal located in a "central" country is just as difficult as being accepted in a toll-gated journal, and perhaps even more difficult if they have to plead for funds to pay the publishing charge. Therefore, if getting into a core OA journal is as difficult as being published in a core, tollgated journal, creating an OA journal on the periphery is a good-deal easier.

The gold road journals have no visibility and, for the most part, belong to the fourth quartile regardless of the geographic area of origin. The peripheral regions were found to produce greater output in gold road journals, confirming $\mathrm{H} 2$. These results also reveal a phenomenon holding true for both Europe and North America, permitting us to conclude that the gold road is the one with the lowest visibility in any region. The results invite us to make the following observation: If OA really has some influence by citation advantage, the gold road that is allowing free access to "real" articles should be reaching greater visibility. Conversely, the results demonstrate that these journals (gold road) are less visible as compared to green road journals that achieve greater visibility when in fact only 10 to $20 \%$ of their items are self-archived. Therefore, the question, as previous works have claimed (Gargouri et al., 2010; Norris et al., 2008), is: Which is responsible for the visibility: OA or the quality of the journals?

In addition, this finding could be the key to a paradox that has been mentioned in the literature involving the inclusion of national journals in international databases and an ensuing drop in "impact per capita" of the country, or a difficulty in making impact grow (Zitt \& Bassecoulard, 1998). López Illescas, Moya-Anegón, and Moed (2009) provided evidence that the oncological journals in SCOPUS that are not covered by the WoS tend to be nationally oriented journals; that is, journals that serve mainly national reading audiences, are not (yet) fully integrated into international networks, and may use publication languages other than English. They play a more peripheral role in the international journal communication system, as expressed in their low citation impact. In expanding the set of WoS journals with SCOPUS journals not indexed for the WoS, the countries that profit most in terms of percentage of published documents tend to show a decline in their average citation rate (Chinchilla-Rodríguez, Miguel, Benavent-Pérez \& Moya-Anegón, in press; ChinchillaRodríguez \& SCImago Research Group, 2010).

The change from national to transnational model, in which so many authors and editors participate with sound publishing practices to enhance their international visibility (Zitt, Perrot, \& Barre, 1998), makes necessary a continual revision of the habits behind dissemination of the results of scientific activity, to move away from the periphery and closer to the center of the publishing arena (Bekayac, Petrak, \& Buneta, 1994).

Thus, while OA may facilitate use, this use of data can be affected by factors that do not necessarily contribute to greater visibility. Such factors include publication in a language other than English (i.e., in the mother tongue of the country in question) (Puliselic \& Petrak, 2006), a high degree of self-citation on the part of authors or journals, and a low percentage of international collaboration (ChinchillaRodríguez, Miguel, Benavent-Pérez \& Moya-Anegón, in press; Chinchilla-Rodríguez \& SCImago Research Group, 2010). Furthermore, beyond the issue of OA publishing, it would appear that authors and editors need to exert themselves more in evaluating their habits. Certain practices which may have been common in the past are no longer recommendable, and if they affect the content of articles, they will ultimately hinder journal quality and visibility.

In general terms and from the standpoint of SCOPUS coverage, there is no noteworthy presence of the gold road in SSA\&H except in LAC and other peripheral regions. The gold road has a greater proportion of work in journals belonging to Medicine; Biochemistry, Genetics and Molecular Biology; Areas Related to Medicine; and Earth and Environmental Sciences.The first three coincide with the areas where Björk et al. (2010) found more gold articles than green ones. There would appear, however, to be a greater presence of the gold road in social sciences according to the DOAJ, an OA source of worldwide reference. This partly confirms $\mathrm{H} 1$.

We arrived at significant differences among the different disciplinary groups with regard to the economic model underlying the journals, and also in the regions of Europe, North America, and Asia. The trend in Oceania is unique. In LAC and Africa, however, we could not determine this because of the small sample of green journals. The green road publications outdo the other two types in most of the thematic areas and geographical regions; thus, the gold road:OA ratio is not very clear. At the thematic level, these results are in line with those of Norris (2008).

On the regional level, LAC shows atypical behavior. The fact that LAC is hardly present in green road journals attests to its recent incorporation into the publishing market, where journals have since taken the high (i.e., gold) road. The scarce presence of LAC output in the mainstream mentioned earlier in the literature means that there is scarcely any green-route production. While the green road yields higher results insofar as visibility, with the gold OA road, the boundaries between these two biases are not well-defined. This may be giving rise to some conflicts in the publishing world. Revision of the overriding policies could help orient future recommendations for researchers, institutions, and information managers.

In summary, the results of our study show that the benefits of OA in terms of impact are to be found on the green route. However, what do the results for green journals teach us about OA if so few articles published in them are actually self-archived? Paradoxically, this study shows that this 
advantage is not lent by the OA, per se, since even though the green road journals are the ones with the highest levels of impact, previous studies have revealed that the percentage of articles placed in repositories or hung on websites does not surpass, on average and for all the thematic fields, $12 \%$. We suggest that future research deep in the level of the document. Perhaps we have to distinguish between "potential" and "actual" documents to "isolate" the actual OA papers in green journals, and compare these to nonarchived articles in the same journals.

Notwithstanding, there are important differences in the different disciplinary groups. The area with the greatest presence (Earth Sciences) just barely reached 26\% (Björk et al., 2010). In other words, most articles published in green journals continue to be non-OA-one good reason why it is not possible to attribute their high visibility to free access. In this sense, as mentioned earlier and in agreement with indications of previous authors (Gargouri et al., 2010; Norris et al., 2008), we believe that the greater visibility of green road journals is not a consequence of $\mathrm{OA}$ but rather of the quality of the articles/journals themselves, regardless of their mode of access. It also has been shown that the guaranteed access afforded along the gold road is insufficient for attaining more citation because citation depends, in the final analysis, on the quality of articles.

So why do green road journals attain higher visibility than do the non-OA ones? What determines the difference between these two groups and their respective impact or success? It may be that editors of the more prestigious journals were the first to jump on board with the OA movement via the green path, establishing some sort of self-archiving policy for their articles. As Eysenbach (2006) claimed, OA is a great vehicle for accelerating the dissemination and acknowledgment of research results, which editors of the most prestigious journals have harvested wisely. It would seem that the recommendation to make visible the results of research through repositories, be they institutional or thematic, increases the probability that they be read sooner and therefore cited earlier, but there is no guarantee of such. OA certainly offers more possibilities, but as Moed (2007) claimed, the citation impact of articles deposited in the Condensed Matter section of the preprint server ArXiv observed differences in citation impact of journal articles are mainly due to factors that have no direct relation to $\mathrm{OA}$ in the sense of being freely available.

Nonetheless, it is the quality of contents and the prestige of the journal and of the author and institution what ultimately determine explicit quality in the form of citation. We should therefore not treat OA and visibility as if they have a causeand-effect relationship but rather view them as signs of wise publishing practices with distinctive roots in the generation of scientific knowledge.

\section{Acknowledgment}

We thank Bo-Christer Björk and the referees for corrections and recommendations that helped us improve the analysis.

\section{References}

Abad García, M.F., González Teruel, A., \& Martínez Catalán, C. (2006). Acceso abierto y revistas médicas españolas [Open access and Spanish medical journals]. Medicina Clínica, 127(12), 456-464.

Australian Research Council. (2009). Retrieved from http://www.arc. gov.au/media/releases/media_20Feb09.htm

Bakkalbasi, N., Bauer, K., Glover, J., \& Wang, L. (2006). Three options for citation tracking: Google Scholar, Scopus and Web of Science. BMC Biomedical Digital Libraries, 3, 7. Retrieved from http://www.biodiglib.com/content/3/1/7

Bekavac, A., Petrak, J., \& Buneta, Z. (1994). Citation behavior and place of publication in the authors from the scientific periphery: A matter of quality? Information Processing \& Management, 30(1), 33-42.

Bessemer, H. (2006). Gathering evidence about the effectiveness of "open access" publishing policies in agriculture. Retrieved from http:// agriscontent.wordpress.com/2006/08/23/gathering-evidence-about-theeffectiveness-of- $\%$ e $2 \% 80 \% 9$ copen-access $\%$ e $\% 80 \% 9 \mathrm{~d}$-publishing-pol icies-in-agriculture

Björk, B.C., Roos, A., \& Lauri, M. (2008). Global annual volume of peer reviewed scholarly articles and the share available via different Open Access options. Proceedings of the International Conference on Electronic Publishing (ElPub 2008), Open Scholarship: Authority, Community and Sustainability in the Age of Web 2.0, Toronto. Retrieved from http://oacs.shh.fi/publications/elpub-2008.pdf

Björk, B.C., Welling, P., Laakso, M., Majlender, P., Hedlund, T., \& Guônason, G. (2010). Open access to the scientific journal literature: Situation 2009. PLoS ONE, 5(6). Retrieved from www.ncbi.nlm.nih.gov/ pmc/articles/PMC2890572

Bollen, J., Van de Sompel, H., Hagberg, A., \& Chute, R. (2009). A principal component analysis of 39 scientific impact measures. PLoS ONE, 4(6). Retrieved from http://www.plosone.org/article/info:doi/10.1371/ journal.pone.0006022

Borgman, C.L., \& Furner, J. (2002). Scholarly communication and bibliometrics. Annual Review of Information Science and Technology, 36, 3-72.

Bosman, J., Van Mourik, I., Rasch, M., \& Verhoeff, H. (2006). Scopus reviewed and compared. The coverage and functionality of the citation database Scopus, including comparisons with Web of Science and Google Scholar. Utrecht, The Netherlands: Utrecht University Library. Retrieved from http://igitur-archive.library.uu.nl/DARLIN/ 2006-1220-200432/Scopus\%20doorgelicht\%20\&\%20vergeleken\%20$\% 20$ translated.pdf

Braun, T., Glänzel, W., \& Schubert, A. (2000). How balanced is the Science Citation Index's journal coverage? A preliminary overview of macrolevel statistical data. In B. Cronin \& H.B. Atkins (Eds.), The Web of Knowledge-A Festschrift in honor of Eugene Garfield (pp. 251-277). Medford, NJ: Information Today.

Budapest Open Access Initiative. (2001). Budapest, Hungary: Open Society Institute. Retrieved from http://www.soros.org/openaccess/read. shtml

Calver, M.C., \& Bradley, J.S. (2010). Patterns of citations of open access and non-open access Conservation Biology Journal and book chapters. Conservation Biology, 24(3), 872-880.

Chan, L. (2004). Supporting and enhancing scholarship in the digital age: The role of open access institutional repositories. Canadian Journal of Communication, 29, 277-300. Retrieved from http://eprints.rclis.org/ archive/00002590/

Chinchilla-Rodríguez, Z., Miguel, S., Benavent-Pérez, M., \& Moya-Anegön, F. (in press). La colaboración científica intrarregional y extrarregional de los países latinoamericanos en el área de Medicina [The intra-and-extraregional scientific collaboration in Latin American countries in the area of Medicine]. Revista Española de Documentación Científica.

Chinchilla-Rodríguez, Z., \& SCImago Research Group (2010, June). Analysis of scientific domains using Scopus-based scientometric tools: Experiences of the SCImago Research Group. Paper presented at the XV International Scientific Congress (CNIC 2010) I International Workshop on Scientometric Studies Related to the Biomedical Sciences. 
Havana, Cuba. Retrieved from: http://www.scimago.es/zaida/analysis_ scientometrics_domains_zaida_chinchilla_cnic2010_pptx.ppt

Codina, L. (2005). Scopus: El mayor navegador científico de la web [Scopus: The greatest scientist of the web browser]. El profesional de la información, 14(1), 44-49.

Craig, I.D., Plume, A.M., McVeigh, M.E., Pringle, J., \& Amin, M. (2007). Do open access articles have greater citation impact? A critical review of the literature. Journal of Informetrics, 1(3), 239-248. Retrieved from http://www.publishingresearch.net/CitationsSummaryPaper3_000.pdf.pdf

Davis, P.M., Lewenstein, B.V., Simon, D.H., Booth, J.P., \& Connolly, M.J.L. (2008). Open access publishing, article downloads, and citations: Randomized controlled trial. BMJ, 337:a568. doi:10.1136/bmj.a568.

Davis, P.M., \& Price, J.S. (2006). eJournal interface can influence usage statistics: Implications for libraries, publishers and project COUNTER. Journal of the American Society for Information and Science Technology, 57(9), 1243-1248.

Deis, L.F., \& Goodman, D. (2006). Update on Scopus. The Charleston Advisor, 7(3). Retrieved from http://charlestonco.com/comp.cfm?id=55

Engels, A., Ruschenburg, T., \& Weingart, P. (2005). Recent internationalization of global environmental change research in Germany and the U.S. Scientometrics, 62(1), 67-85

Eysenbach, G. (2006). Citation advantage of open access articles. PLOS Biology, 4, 692-698. Retrieved from http://www.plosbiology.org/article/ info:doi/10.1371/journal.pbio.0040157

Falagas, M.E., Pitsouni, E.I., Malietzis, G.A., \& Pappas, G. (2008). Comparison of PubMed, Scopus, Web of Science, and Google Scholar: Strengths and weaknesses. FASEB Journal, 22, 338-342

Fingerman, S. (2005). Scopus: Profusion and confusion. Online, 29(2), 36-38.

Fingerman, S. (2006). Web of Science and Scopus: Current features and capabilities. Issues in Science and Technology Librarianship, 48(Fall). Retrieved from http://www.istl.org/06-fall/electronic2.html

Gargouri, Y., Hajjem, C., Lariviere, V., Gingras, Y., Brody, T., Carr, L., \& Harnad, S. (2010). Self-selected or mandated, open access increases citation impact for higher quality research. PLoS ONE 5(10): e13636. doi:10.1371/journal.pone.0013636

González-Pereira, B., Guerrero-Bote, V., \& Moya-Anegón, F. (2010). A new approach to the metric of journal's scientific prestige: The SJR indicator Journal of Informetrics, 4(3), 379-391.

Hajjem, C., Harnad, S., \& Gingras, Y. (2005). Ten-year cross-disciplinary comparison of the growth of open access and how it increases research citation impact. IEEE Data Engineering Bulletin, 28, 39-47. Retrieved from http://eprints.ecs.soton.ac.uk/11688/

Harnad, S. (2007). Citation advantage for OA self-archiving is independent of journal impact factor, article age, and number of co-authors. arXiv:cs/0701136. Retrieved from http://openaccess.eprints.org/index. php?/archives/2007/01/17.htm

Harnad, S., Brody, T., Vallieres, F., Carr, L., Hitchcock, S., Gingras, Y., Oppenheim, C., \& Hilfet, E.R. (2004). The access/impact problem and the green and gold roads to open access. Serials Review, 30(4), 310-314.

Harnad, S., Brody, T., Vallières, F., Carr, L., Hitchcock, S., Gingras, Y., Oppenheim, C., \& Hilfet, E.R. (2008). The access/impact problem and the green and gold roads to open access: An update. Serials Review, 34(1) $36-40$.

Jacsó, P. (2005). As we may search-Comparison of major features of the Web of Science, Scopus, and Google Scholar citation-based and citationenhanced databases. Current Science, 89(9), 1537-1547. Retrieved from http://www.ias.ac.in/currsci/nov102005/1537.pdf

Jacsó, P. (2006). Open access to scholarly indexing/abstracting information. Online Information Review, 30(4), 461-468.

Jacsó, P. (2008a). Testing the calculation of a realistic h-index in Google Scholar, Scopus, and Web of Science for F.W. Lancaster. Library Trends, 56(4), 784-815

Jacsó, P. (2008b). The plausibility of computing the h-index of scholarly productivity and impact using reference-enhanced databases. Online Information Review, 32(2), 266-283.
Jacsó, P. (2008c). The pros and cons of computing the h-index using Scopus. Online Information Review, 32(4), 524-535.

Jacsó, P. (2010). Comparison of journal impact rankings in the SCImago Journal \& Country Rank and the Journal Citation Reports databases. Online Information Review, 34(4), 642-657.

Keresztesi, M. (1982). The science of bibliography: Theoretical implications for bibliographic instruction. In C. Oberman \& K. Strauch (Eds.), Theories of bibliographic education (pp. 1-26). New York: Bowker.

Kurtz, M.J., Eichhorn, G., Accomazzi, A., Grant, C.S., Demleitner, M., \& Murray, S.S. (2005). The effect of use and access on citations. Information Processing \& Management, 41(6), 1395-1402.

La Guardia, C. (2005). E-views and reviews: Scopus vs Web of Science. Retrieved from http://www.libraryjournal.com/article/CA491154. $\mathrm{html} \% 22$

Lawrence, S. (2001). Online or invisible? Nature, 411, 521. Retrieved from http://www.neci.nec.com/lawrence/papers/online-nature01/

López-Illescas, C., Moya-Anegón, F. de, \& Moed, H.F. (2009). Comparing bibliometric country-by-country rankings derived from the Web of Science and Scopus: The effect of poorly cited journals in oncology. Journal of Information Science, 35, 244-256.

Martin, B.R. (1996). The use of multiple indicators in the assessment of basic research. Scientometrics, 36(3), 343-362.

Moed, H.F. (2007). The effect of "open access" upon citation impact: An analysis of ArXiv's condensed matter section. Journal of the American Society of Information Science and Technology, 58, 2047-2054.

Moed, H.F., Van Leeuwen, T.N., \& Reedijk, J. (1999). Towards appropriate indicators of journal impact. Scientometrics, 46(3), 575-589.

Morillo, F., Fernández, M.T., \& Gómez, I. (1999). Evolution of Spanish journals in the international scene. Research Evaluation, 9(2), 71-76.

Moya-Anegón, F. (Dir.), \& Chinchilla-Rodríguez, Z. (Coord.). (2009). Indicadores bibliométricos de la actividad científica Española 2007 [Bibliometrics indicators of the Spanish scientific activity]. Madrid: Fundación Española para la Ciencia y la Tecnología.

Moya-Anegón, F., Chinchilla-Rodríguez, Z., Vargas-Quesada, B., CoreraÁlvarez, E., Muñoz-Fernández, F.J., González-Molina, A., \& HerreroSolana, V. (2007). Coverage analysis of Scopus: A journal metric approach. Scientometrics, 73(1), 53-78.

Norris, M., Oppenheim, C., \& Rowland, F. (2008). The citation advantage of open-access articles. Journal of the American Society for Information Science and Technology, 59, 1963-1972.

Pontificia Universidad Católica de Valparaíso. (2009). Directorio de Revistas Open Access reconocidas por el ISI Web of Science [Directory of Open Access journals recognized by ISI Web of Science]. Retrieved from http://www.ejbiotechnology.cl/proyecto/index.php

Puliselic, L., \& Petrak, J. (2006). Is it enough to change the language? A case study of Croation biomedical journals. Learned Publishing, 19(4), 299-306.

Rordorf, D. (2010). Continued growth of the impact factors of MDPI open access journals. Molecules, 15, 4450-4451. doi:10.3390/molecules 15064450

Rousseau, R., \& the STIMULATE 8 Group. (2009). On the relation between the WoS impact factor, the Eigenfactor, the SCImago Journal Rank, the Article Influence Score and the journal h-index. E-LIS archive, ID: 16448. Retrieved from http://eprints.rclis.org/16448/

SCImago. (2007). SCImago journal \& country rank: un nuevo portal, dos nuevos rankings. El profesional de la información, 16(6), 645-646. Retrieved from http://www.elprofesionaldelainformacion.com/ contenidos/2007/noviembre/11.pdf

Swan, A. (2010). The open access citation advantage. Studies and results to date [Tech. Rep.]. Retrieved from University of Southampton School of Electronics \& Computer Science website: http://eprints.ecs.soton. ac.uk/18516/

Tomizawa, H. (2008). Custom data fuels OECD's innovation strategy, Research Trends, 8, 3 .

Turk, N. (2008). Citation impact of Open Access journals. New Library World, 109(1/2), 65-74. 
Wagner, A.B. (2010). Open access citation Advantage: An annotated bibliography. Issues in Science and Technology Librarianship, 60(Winter). Retrieved from http://www.istl.org/10-winter/article2.html

Warlick, S.E., \& Vaughan, K.T.L. (2007). Factors influencing publication choice: Why faculty choose open access. Biomedical Digital Library, 4, 1. Retrieved from http://www.pubmedcentral.nih.gov/picrender.fcgi?artid= $1832213 \&$ blobtype $=$ pdf \& tool $=$ pmcentrez
Zitt, M., \& Bassecoulard, E. (1998). Internationalization of scientific journals: A measurement based on publication and citation scope. Scientometrics, 41(1-2), 255-271.

Zitt, M., Perrot, F., \& Barre, R. (1998). The transition from "national" to "transnational" model and related measures of countries' performance. Journal of the American Society for Information Science, 49, $30-42$. 